\title{
New perspectives for rainwater conservation and water-sensitive urban design for the Bangalore metropolitan area
}

\author{
U. Rajeshuni, P. Dongare \& V. A. Sheriff \\ Department of Architecture, Habitat design, BMS College of Engineering \\ Autonomous under Visveswaraya Technological University, India
}

\begin{abstract}
Several researchers have predicted that more than half the global population will be living in urban areas by 2030 . This puts an unimaginable demand for water in the population dense urban agglomerations globally. It also creates the need and opportunity for a water- sensitive approach to urban planning and urban design. The population of Bangalore, the IT capital of India, has grown manifold in recent times as result of the impact of the IT industry and with this has grown the demand for water. Bangalore is also known as city of lakes but recently number of these lakes has been diminishing due to indiscriminate urbanization. In 1960, the number of lakes was 262 and currently it has been declined to 81.This crisis in diminishing lakes has affected the conservation of rainwater in the urban area and hence the need for the harvesting of rainwater in the urbanized area. The paper explores design solutions for the conservation of rainwater in the Bangalore Metropolitan Area which are simple enough to be applied by the stakeholders and urban bodies in other metropolitan areas too.
\end{abstract}

Keywords: urban area, conservation, percolation, Bangalore, rainwater, redesign, perspective, ecology, bye-laws, sustainability.

\section{Introduction}

Cities, towns and villages all have a long and intimate relationship with water and were historically located around a water source, watercourse or coastline as the focal point for life and trade. In modern times, not only do we depend on clean water supply for our daily needs, but we also depend on water to grow our 
food and produce resources, to transport our goods and waste, beautify our urban areas and provide fun and recreation. Water is often central to the identity of a place. Yet the relationship between the places we live and the water resources we depend on is often not prioritized in the development, design and evolution of those places. Water shortages, flooding and watercourse pollution are all signs of stress where developed areas have a troubled interaction with the natural water cycle and where, conversely, water has become a risk or a nuisance rather than an asset or an opportunity.

Bangalore is such an example where the city had an intimate relationship with the water. Geographically, the Bangalore urban area does not have a river or a sea edge, hence for a sustainable living the founder of the city Kempe Gowda-1 created catchment areas for the rainwater in form of check dams or 'kattes' which resulted in water collecting in the keres or kuntes popularly referred to as the lakes of Bangalore. This water was primarily used for the agrarian purpose with potable water being withdrawn from conventional type of wells. This type of water system is called the 'karanji' system. In recent years this eco-sensitive approach towards collection and use of rainwater has been undermined. This along with extensive hardscaping which does not allow the percolation of rainwater has resulted in the lowering of the water table. Groundwater is also being contaminated with sewage due to lack of maintenance and monitoring and hence, the conventional wells for potable water cannot be used. Potable water is now being drawn from the underlying aquifers using bore-wells and the municipal water supply is drawn from Cauvery River.

\section{Methodology}

Harvesting water is an integrated system. To achieve a reasonable improvement and to provide solution it becomes important to understand the spatial structure both natural and manmade features before any solutions are given. As these solutions have to be given at various levels such as from regional level, city level, Planning district level, street level to site level there are various layers that need to be analysed for each level.

At a regional level, (fig. 1) maps such as valley map, water shed map, and slope maps have to be analysed in which the challenge lies in understanding the geography and flow of water and to select locations which are suitable enough to be protected from being developed for settlement i.e. natural areas that need to be conserved like valleys and environmentally or ecologically sensitive areas.

The challenge at city level lies in regulation of development to tie in with the preservation of valley lines identified at the regional level. Existence of open spaces and water bodies against the pressures and demand of development is forever an ongoing struggle in the city of Bangalore.

At planning district level, it becomes important to monitor the development strategies provided at city level are implemented by the various clients.

The streets are the veins of the city; these streets are also the carriers of the utility structures. It becomes important to understand the orientation of these streets in a view to select the best storm water network which will in turn 

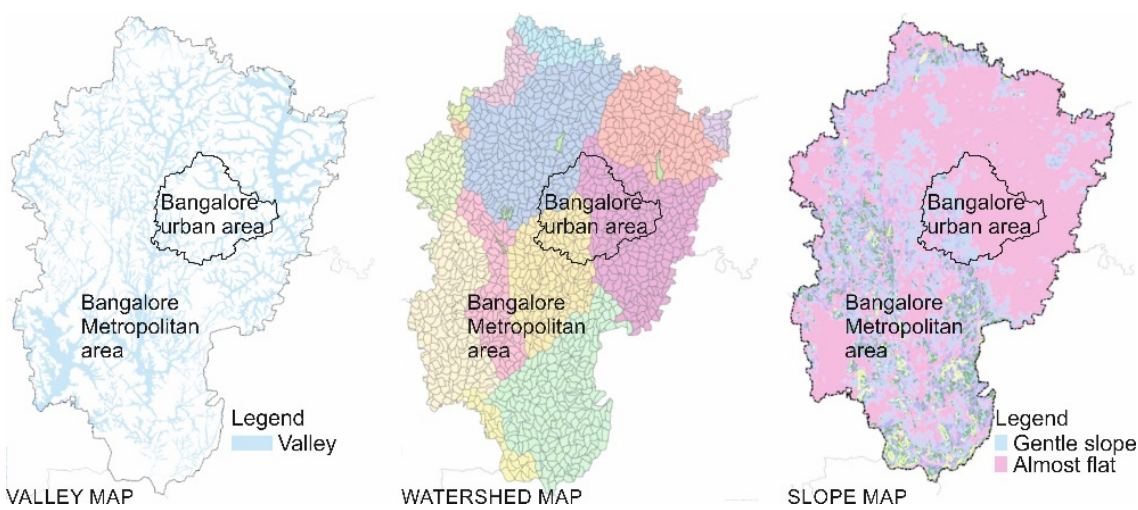

Figure 1: Bangalore urban area highlighted on maps of the Valley system, Water shed system and slope layout of Bangalore metropolitan region from the Structure Plan of the Bangalore Metropolitan and Regional Development Authority [1].

connect to the lakes at the city level. Also sometimes areas of few streets are much higher than prescribed standards like street widths, and such areas streets can be noted for interventions.

Effective policies exist at site level; implementation of the same is the recurring issue. More effective methods to reduce the runoff from individual sites to the street level and hence city level infrastructure should be taken into consideration.

\section{Redesigning}

The issue to be addressed is to identify the location for collection of water and to maximize the percolation of water within the built urban areas to direct the development which is in harmony to harvest the rainwater as it was done when the Bangalore city was established. The possible solutions are listed below according to various scales and levels.

At a regional level, the identified valley lines and lower contours should be selected for development of lakes and water bodies. A connective network system should be established within the lakes and water bodies both beyond the urban areas and within the urban area which will ensures the distribution of the water within the metropolitan region. These network systems should be controlled by check dams to ensure the quantity of water distribution and direction of distribution within the region. This established direction of flow of water system will ensure the quick flow of water and will also help mitigating urban floods.

At city level, regulation (building bylaws/zoning regulations) are one of the tools which can be used to ensure the undisrupted flow of rainwater to the kerekunte and rajakalvey systems and valleys which are identified at regional level. Now cities have become complex in their spatial structure, for such a case the 
green zones such as parks and green buffers become point of termination where the directed water within the area can be allowed to collect and percolate. This collected water can also be reused for urban purposes.

The development of Bangalore must take place within the natural framework defined by valleys, tanks and lakes. The priority of this objective is to protect natural water resources and to facilitate sustainable development. The three major valley of the Bangalore urban area are as shown in fig. 2.

Within these valleys, the existing lakes, which are marked in red should be developed to the potential to accommodate the precipitated water, Also a network system can be establishes to connect the valleys within the urban area and to the lakes in regional areas. Fig. 3 shows the natural areas within the urban

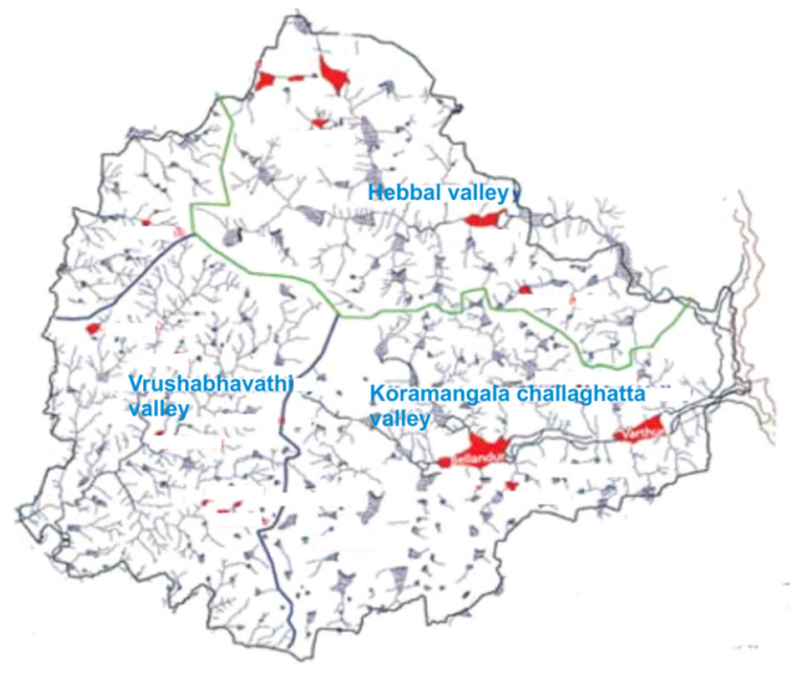

Figure 2: $\quad$ Valley and ridge map for the Bangalore urban area [2].

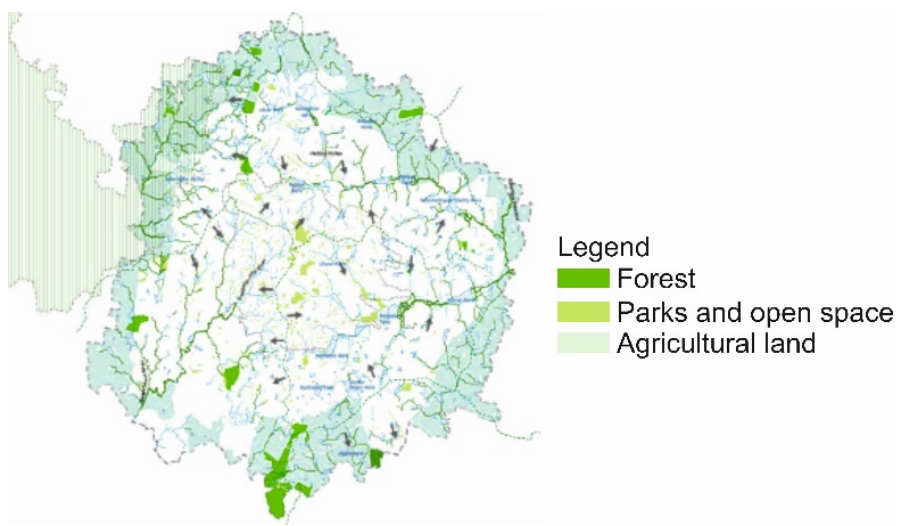

Figure 3: Natural area map (Bangalore urban area) [3]. 
limits. These areas should be regulated under the byelaws to keep clear the valley lines from development and the percolation surfaces in terms of green belt, state forest and parks and grounds.

One of the low lying areas known as Sivaji Nagar which is the oldest part of the Bangalore city is as shown in fig. 4. Valley lines were established in the area and canals were built to connect to the further lakes which pass through this area. Due to urbanization and high level of hard pavement and building on the valley line the flow of the water is distributed and the region experiences urban flood. As a design solution in such areas the direction of water runoff should be identified and accordingly they have to be cleared of development.

The Bangalore Metropolitan area is divided into 47 number of planning districts as shown in fig. 5. These districts are further classified into Core Area or

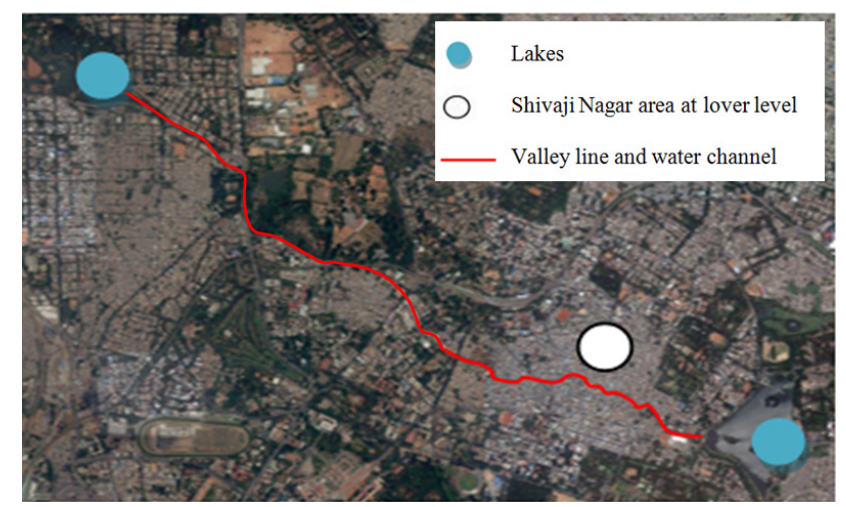

Figure 4: Demonstration of urban growth along the ridge line in Shivaji nagar area [4].

Core Ring Planning Districts, Intermediate Area or Intermediate Ring Planning Districts, Outer Area or Outer Ring Planning Districts based on urbanization viz. intensely urbanized, moderately urbanized and urbanizing. The byelaws are specific for the type of planning districts.

At this urban district/planning district level, locating parks and playgrounds, controlling hardscaping in large landholdings like educational campuses, health campuses, gated communities, administrative areas amongst others become important to increase the percolation of the rainwater. The following images showcase the solutions that can be adopted.

At street level, it becomes important to plan and design the streets in terms of the direction, slope and material to address issues relating to rainwater harvesting and conservation. At local level the locations at lower level should be identified and those areas should be paved with material which allows percolation or with porous paving. Within the built urban environment traffic islands as shown in fig. 9 can be used as pockets where percolations can be allowed by creating Bio retention Basin as shown in fig. 10. 


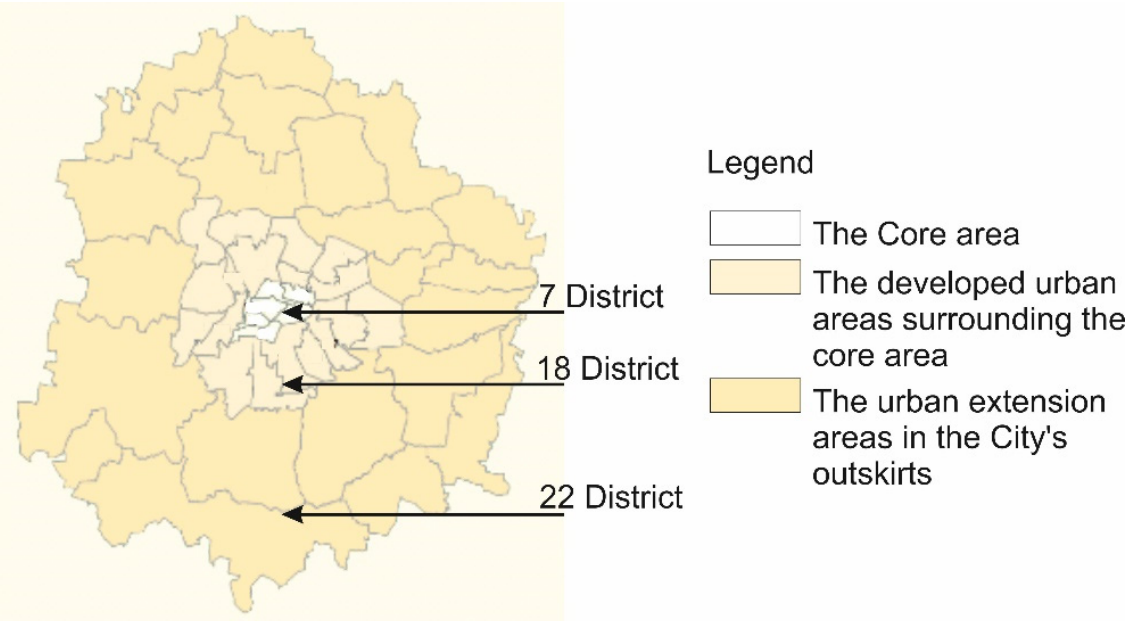

Figure 5: Bangalore planning district map [5].

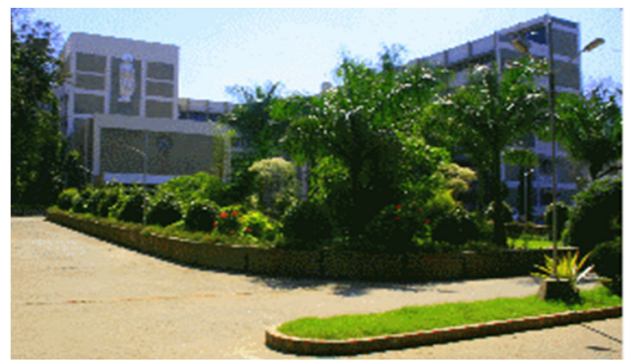

Figure 6: St John's Hospital is a medical institution of world repute and it has a well-developed system of green open spaces between the different building blocks [6].

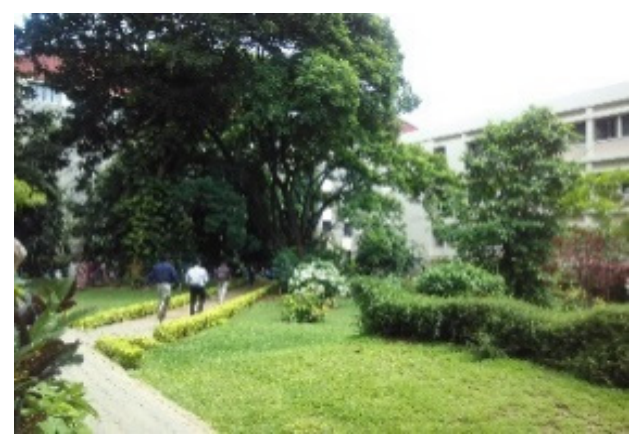

Figure 7: The BMS College of Engineering is the oldest private engineering college in India. It is a 'green' campus with well-developed rainwater harvesting system with the harvested rainwater being utilized to maintain its extensive and beautiful gardens. 


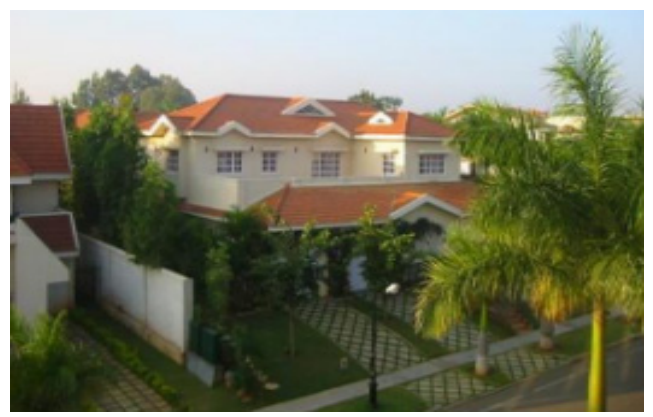

Figure 8: Increased percolation surface through conscious use of materials [7].

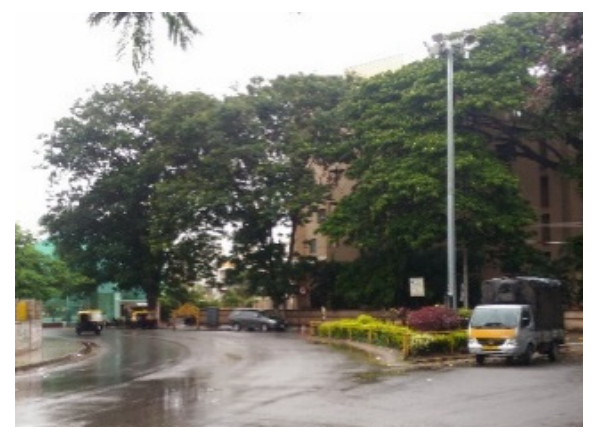

Figure 9: Traffic island at lower level then surrounding.

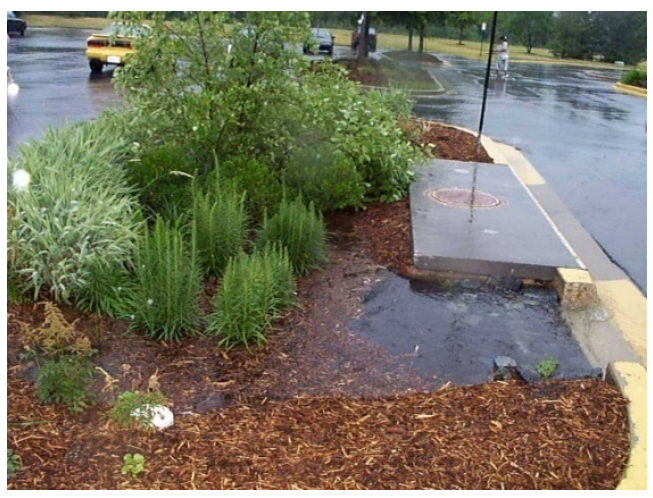

Figure 10: Bio retention basin [8].

Another workable location are major junctions which cover huge areas, in these locations only at junctions porous pavers can be used. This will increase the percolation surface and also beautifies the junction. For example, fig. 11 demonstrated the design pattern for South end circle in the Bangalore area. 


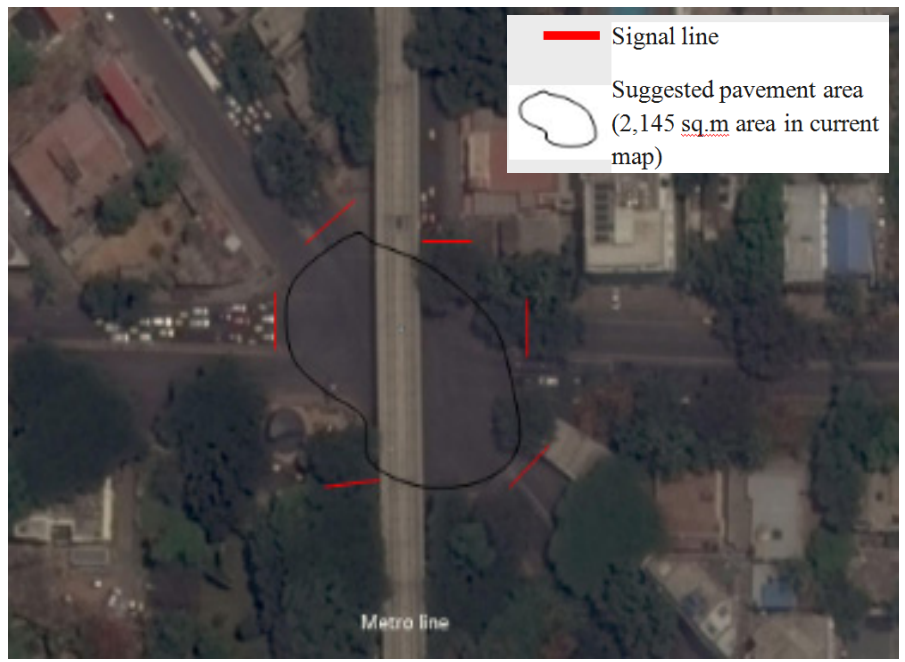

Figure 11: Suggested design pattern for a traffic junction [9].

At site level, policies for rainwater harvesting are already in place in Bangalore city. This system ensures the catchment from terrace area but the water falling over rest of unbuilt area is unmonitored. To increase the percolation in these areas hardscaping should be avoided or porous materials should be used if necessary. This can be achieved by specifying ratio of porous to paved area in addition to the ground coverage specified in the Land Use Zonal Regulations of the Draft Master Plan 2030.

Table 1: $\quad$ FAR and ground coverage in residential (main) as provided in bylaws with the column on right indicating the proposed softscape area.

\begin{tabular}{|c|c|c|c|c|c|}
\hline Sl. no & $\begin{array}{c}\text { Plot size } \\
\text { (sq. M) }\end{array}$ & $\begin{array}{c}\text { Ground coverage } \\
(\max )\end{array}$ & FAR & Road width (m) & $\begin{array}{c}\text { Proposed } \\
\text { softscape } \\
\text { area (min) }\end{array}$ \\
\hline 1 & Up to 360 & Up to 75\% & 1.75 & Up to 12.0 & $10 \%$ \\
\hline 2 & $\begin{array}{c}\text { Above } 360, \text { up } \\
\text { to } 1000\end{array}$ & Up to 65\% & 2.25 & $\begin{array}{c}\text { Above } 12.0, \text { up } \\
\text { to } 18.0\end{array}$ & $10 \%$ \\
\hline 3 & $\begin{array}{c}\text { Above } 1000, \text { up } \\
\text { to } 2000\end{array}$ & Up to 60\% & 2.50 & $\begin{array}{c}\text { Above } 18.0, \text { up } \\
\text { to } 24.0\end{array}$ & $15 \%$ \\
\hline 4 & $\begin{array}{c}\text { Above } 2000, \text { up } \\
\text { to } 4000\end{array}$ & Up to 55\% & 3.00 & $\begin{array}{c}\text { Above } 24.0, \text { up } \\
\text { to } 30.0\end{array}$ & $15 \%$ \\
\hline 5 & $\begin{array}{c}\text { Above } 4000, \text { up } \\
\text { to } 20,000\end{array}$ & Up to 50\% & 3.25 & Above 30 & $20 \%$ \\
\hline
\end{tabular}


The following images demonstrated the influence of the proposed softscaping area that can be achieved at site level including plot level and at community layout planning level.

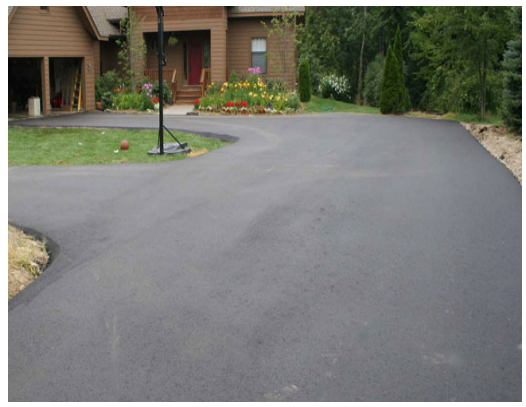

Figure 12: View of pavement without softscaping for a residential unit [10].

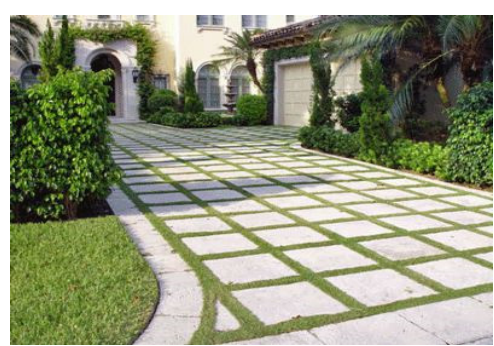

Figure 13: View of pavement with softscaping for a residential unit [11].

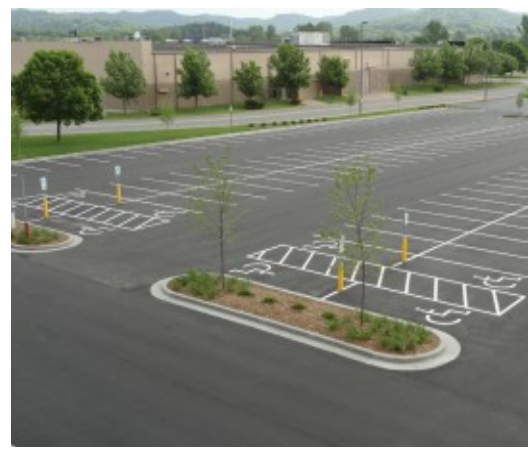

Figure 14: View of pavement without softscaping for a community parking area [12]. 


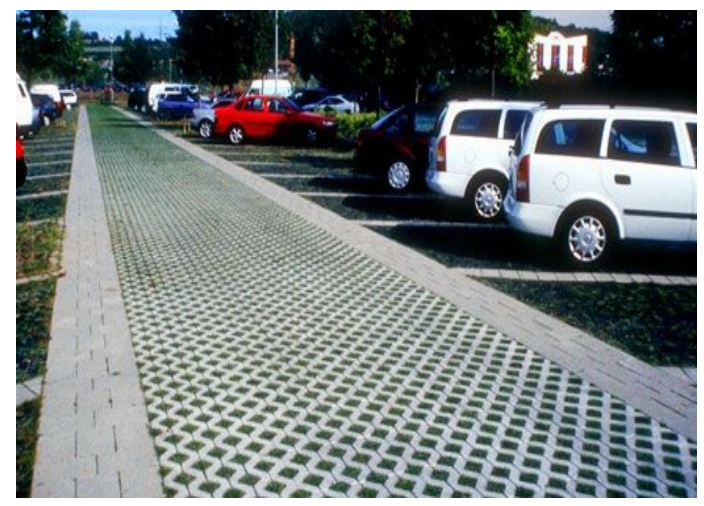

Figure 15: View of pavement with softscaping for a community parking area [13].

\section{Conclusion}

The solutions highlighted in the paper are simple enough to be adapted by the stake holders and urban bodies with the use of available advanced technology and implementation tools. The use of modern technology will also be beneficial to achieve a higher rate of water recharge in urban area. At the site/plot scale measures would include specifying ratio of porous to paved area in addition to the ground coverage specified in the Land use Zonal Regulations of the Draft Master Plan 2030. At street/road scale again limiting the hardscaping by using porous pavers, swales as storm water and others needs to be considered as an appropriate measure to allow percolation of rainwater into the ground. At the urban district/planning district locating parks and playgrounds, controlling hardscaping in large landholdings like educational campuses, health campuses, gated communities, administrative areas amongst others. At the city/metropolitan scale with appropriate policies for prevention of indiscriminate urbanization in the natural valleys, conservation of natural valley systems, conservation of the storm water kere-kunte systems amongst others.

\section{References}

[1] BMRDA (Banglore Metropolitan Region Development Authority; Bangalore Metropolitan Region Revised Structure Plan - 2031; Group SCE India Pvt. Ltd., pp. 1-346; 2015.

[2] Subhash Chandra NS; Vanishing lakes: Time to act now; Deccan Herald; Saturday 02 July 2016; 2009, http://www.deccanherald.com/content/ 25285/vanishing-lakes-time-act-now.html

[3] BDA (Banglore Development Authority Banglore); Vision Document; Bangalore master plan 2015; Volume 1; page 43; 2007.

[4] www.googleearth.com (accessed on 27-6-2016). 
[5] BDA (Banglore Development Authority Banglore); Revise master Plan 2015 Banglore; Volume 2; Page 5; 2007.

[6] St. John's National Academy of Health Sciences, http://www.stjohns.in /hospital

[7] Property wala ,https://www.propertywala.com/P95221247

[8] http://dnr.wi.gov/topic/stormwater/learn_more/photos.html

[9] www.googleearth.com (accessed on 27-6-2016).

[10] Allied constructions, http://www.alliedasphalt.com/residential-asphaltpaving-services.html

[11] Griffith A.; Grass Driveways; DIY Chatroom; 2012, http://thestyledlife blog.blogspot.in/2012/06/grass-driveways.html

[12] Parking lot, http://www.myasphaltpavingproject.com/paving-applications/ parking-lots/

[13] Inhabitat, http://inhabitat.com/pervious-paving-reduces-stormwater-runoff/ 